\title{
Geotechnical Site Investigation Using S-waves with Implications for Ground Motion Analysis
}

\section{Študija geotehnične preiskave lokacije z valovi S ob upoštevanju premikov tal}

\author{
Bilal Hassan', *, Stephen D. Butt', Charles A. Hurich² \\ ${ }^{1}$ Faculty of Engineering and Applied Science, Memorial University of Newfoundland, Canada \\ ${ }^{2}$ Department of Earth Sciences, Memorial University of Newfoundland, Canada \\ *p94bh@mun.ca
}

\begin{abstract}
Evaluation results of shear wave attenuation-based ground motion restricted by fracture orientation and rheology, from among those of an extended experimental study, are presented herein. The issues of competence of fractured bedrock dynamically disturbed multilaterally are assessed. Disturbance is primarily modelled by Sh and Sv stimulation, given fracture orientation, while subjected to direct fracture stress regime conditions varying in time. Hence, directionalities of polarisation and stress are taken into consideration simultaneously following simple site-specific non-erodetic approach. Comparison of spectral curves and spectral ratio curves of attenuation with respect to variations of direction and stress emphasise the amplification of the 'seismic response' in one direction compared to the other, i.e. vertical vs. horizontal, in terms of weighing possibilities of or predicting structural integrity against failure. The composite analyses of multiple spectral curves not only enable determination of the orientation of the fracture set/s in space but also allow inferring the nature of more amplified response perpendicular to the crack surface compared to that of a response parallel to the crack surface.
\end{abstract}

Key words: site investigation, attenuation examination, ground motions, S-wave evaluation, seismic amplification
Povzetek

Iz izvedene obsežnejše eksperimentalne raziskave so prikazani rezultati preiskovanja premikov tal na osnovi ugotavljanja slabitve strižnih valov, omejene $\mathrm{z}$ orientacijo razpok in reološkimi lastnostmi kamnine. Obravnavani so razni vidiki kompetentnosti razpokane kamnine, podvržene večstranskim dinamičnim dislokacijam. Dislokacija je modelirana predvsem s Sh in Sv stimulacijo ob upoštevanju orientacije razpok v okoliščinah neposredne časovno spremenljive obremenitve razpok. Pri tem sta usmerjenost polarizacije in pritiska upoštevani hkrati, sledeč običajni proceduri takih raziskav. Primerjava spektralnih krivulj slabitve in krivulj spektralnih količnikov z ozirom na spreminjanje smeri in pritiska nakazuje ojačenje "seizmičnega odziva" v eni smeri v primerjavi z drugo, t.j. v navpični smeri glede na vodoravno, kar omogoča presojo možnosti ali napovedovanje strukturne odpornosti na porušenje. Kompozitne analize multiplih spektralnih krivulj omogočajo ne le določitev orientacije skupine ali več skupin razpok v prostoru, pač pa tudi opredelitev narave ojačenega odziva pravokotno na ravnino razpok v primerjavi z odzivom vzporedno z njo.

Ključne besede: preiskovanje lokacije, ugotavljanje slabitve, premiki tal, preiskava valov S, seizmično ojačevanje 


\section{Introduction and experimental design}

Stressed primarily due to population increase, in addition to the developing and evolving nature of life style changes, urban inhabitation developments of infrastructure are well paced, quite ahead compared to desirably equi-paced enforcement of well-examined regulatory codes. Further, the design aesthetics and location outweigh considerations of the inherent site characteristic of strength during natural disasters or other agents. At times, not only are observably increased global seismic activity aspects inappropriately assessed, also ignored are the aseismic effects associated with recurring activities and developments of anthropogenic nature, including mining as well as the oil and gas industries mainly. Excess pore pressure and water stress either from rain or seawater intrusions may, in combination, further aggravate the strength properties by physicochemical actions. The actions of such agencies could be more devastating in the case of faulted near-surface bedrock or strata.

Two important issues, relevant to the forthcoming discussion, are naturally deducible, namely, not only are (1) the codes and guiding provisions inadequate, but (2) the assumptions forming the basis of the underlying investigative methods fail to provide sufficient or adequate knowledge required. An attempt is made in the ensuing exposition to investigate the second point as an objective and rationalised exercise, by offering the dynamic evaluation of a laboratory-based fractured bedrock site. An examination of the possibilities of ground motion-associated seismic response amplification is illustratively discussed when propagated by S-wave modes under incremented constant load but variable stress conditions.

For fulfilling the desired study objective, an analogue specimen of natural material was fabricated or constructed to form a meaningful geometry. It comprised six real sandstone slabs of equal length stacked together to be used in multiple experiments. The final sample specimen consisted of all six rectangular slabs, stacked together to offer different normal or planar fracture contacts or interface areas subjected to load as the slabs were of equal thickness (or depth) and lengths but different widths. Sections of slabs were cut out of a standard circular 54-mm-diameter-core typical bedrock retrieved from a glass sandstone outcrop, additional details of which can be obtained from [1]. The length of the finished sample specimen was about $108 \mathrm{~mm}$, with a depth of $65 \mathrm{~mm}$ (including five interfaces) given some tolerance of about $1 \mathrm{~mm}$, with each slab being approximately $1 \mathrm{~cm}$ in thickness. Uniformly distributed load normal to the external or extreme surface was applied in nine incremental load steps ranging from $0 \mathrm{~kg}$ to (about) $1000 \mathrm{~kg}$ for successive loading-unloading repeated cycles. While considering a single focussed source, ultrasonic shear waves were transmitted and recorded along the cracks at the opposite end of the long axis, with source and receiver positions mirroring. Figure 1a shows the size and geometrical details of the slab analogue, whereas the schematic illustration of Figure $1 \mathrm{~b}$ shows the details of acquisition and the loading configuration. In order to capture the combined effects of rheology and direction variability, waveforms were recorded by angularly displacing or varying the source and receiver orientations, together and relative, fixed at the same contact point, in azimuth, for simulating a multi-azimuth type acquisition. The manner of azimuthal displacements within the plane of polarisation can be understood from the details of Figure $1 \mathrm{~b}$.

Since the analogue specimen was loaded or stressed uniaxially, the applied load was parallel to the so-called horizontal axis of symmetry and only perpendicular to the fracture planes. It allowed simulating a configuration wherein the minimum horizontal stress is zero, as compared to a certain varying maximum horizontal stress normal to the plane of aligned vertical fractures, relative to the variable interfacial contact areas in comparison, scaling wise. Due to the restriction of design of the loading frame and loading platens, the sample specimen had to be loaded oriented such that the vertical axis of symmetry (long axis) would be horizontal and the axis along the maximum horizontal stress direction (normal) as vertical, understandable also from the depiction in Figure1a and Figure 1b. Anisotropy of rheological effects was induced by causing a cyclic stress variation. The stress variation was achieved by varying the ap- 


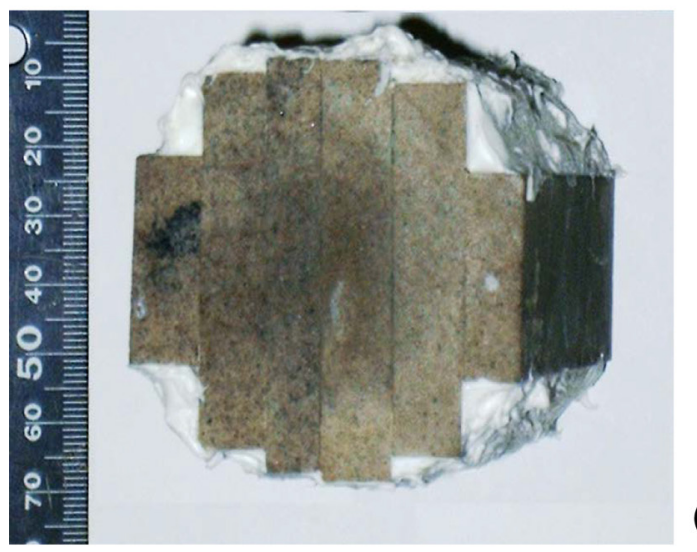

(a)

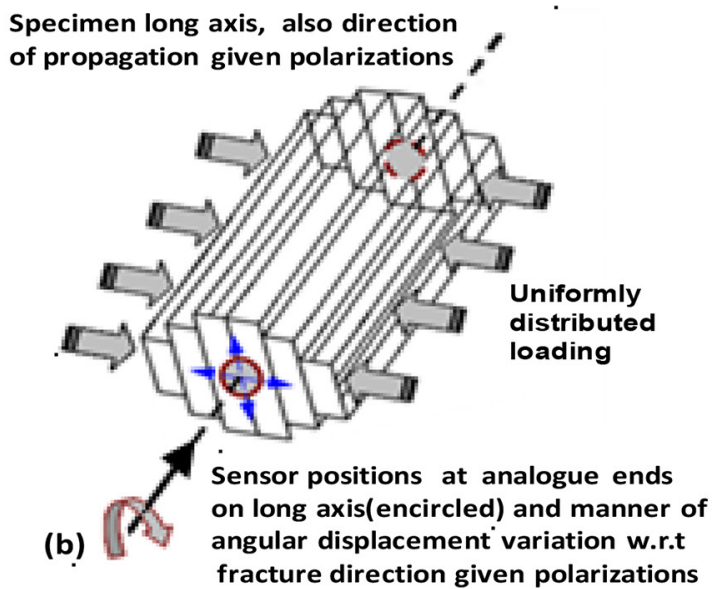

Figure 1: (a) Stacked arrangement of the slabs of real sandstone synthesised as a structural analogue. (b) Schematic illustration of the details of S-wave stimulation and acquisition, as well as the loading distribution (modified from [2]).

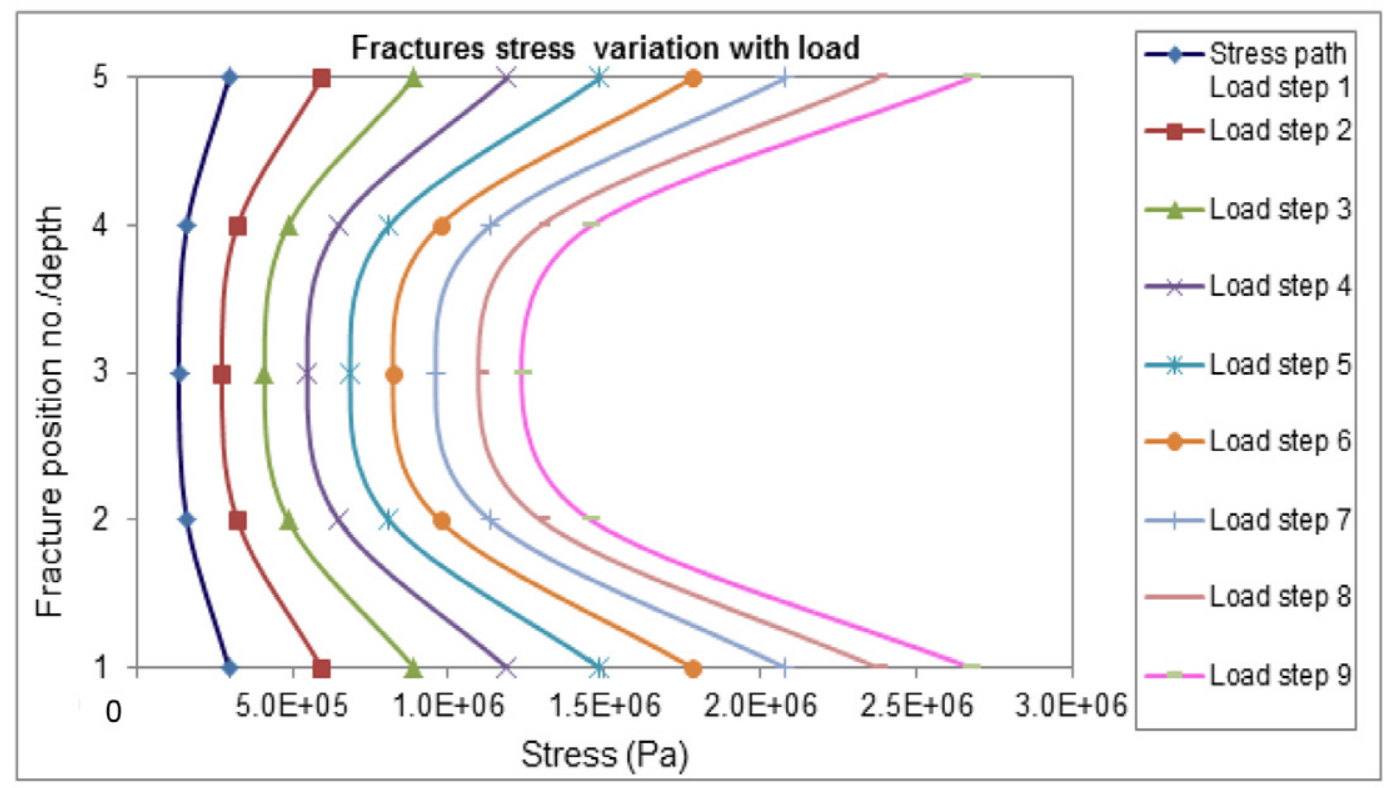

Figure 2: Simplified representation (cyclical hysteresis ignored) of the variation of direct stress, normal to the fracture planes of the analogue, with load incremented in equal steps (1-9), with fracture 3 at the middle or half depth (modified from [2]).

plied uniaxial load in nine steps. The details of aspects of stepwise controlled loading scheme in terms of influence are depicted in Figure 2. The load was varied from a minimum of $0 \mathrm{~kg}$ to about $900 \mathrm{~kg}$ cyclically (i.e. loading-unloading, each step with same magnitude but not at a constant rate).

Each complete loading-unloading cycle was replicated to give four 'load variation' half cycles for each relative specimen direction or azimuth to enable measurements starting from $0^{\circ}$ through $180^{\circ}$, with increments of $30^{\circ}$ with respect to (w.r.t.) the fracture plane trajectory on the end face normal to the long axis, where reciprocal confirmatory measurements were also taken for each stress state, illustrated further in the next section on analyses. Given the hinted rationale, the acquired data structuring, based on the geometric, symmetric and topological characteristics of the analogue sample as a seismically stimulated site in a stress field, provided sufficient detail to study such important parameters as direction-dependent amplitude amplification of deformation response by spectral comparison and assessment of strength properties by spectral ratio curves in comple- 
mentary sense. Complete details of acquired data, reduction and structuring, as well as the manner in which cyclical loading was achieved can be obtained from [2].

\section{Theory behind the analyses}

Apart from loss of life due to localised site conditions of failure during earthquakes, other factors that exacerbate the damage include topography and relief, basin effects and ground failure; however, the primary factor is the site-specific amplification of the ground motions as an increase of the seismic response. The amplification occurs because the natural period of the supporting soil column or strata approaches that of the supported structure or building. Due to the nature of attenuation-based methods as devised to determine ground motion-associated site response implication effects, there is always the need for a better semiquantitative-to-quantitative description of such phenomena for better descriptions, whereas most descriptions or relations of attenuation offer a more qualitative assessment only.

Most of the attenuation relationships account for site effects through a broad site classification system that only categorises them into 'rock and shallow stiff soil', 'deep stiff soil' and 'soft soil' [3].

In order to account for the non-linearities of ground (soil or rock) motion response, a single long period or S factor approach went into obsolescence, for instance, in favour of a combined two-factor approach using Fa and Fv, i.e. shortand long-period factor combined, expected to better describe the ground motion-related amplification response as both the short- and the long-period motions are taken into consideration. With the ground/soil non-linearities increasing the associated seismic hazard, the factors $\mathrm{Fa}$ and $\mathrm{Fv}$ decrease. Their significance, compared to $\mathrm{S}$ factor, lies in the areas of low and medium hazard. The non-linearities associated with the inherent site characteristics are those of geometry/depth, geological material structure and distance from disturbance, in addition to the directionalities of the stimulation or disturbances, non-linear aspects control the nature of possible amplification manifested as spectral content or information and its distribution. Regardless of the difference in the application of S-factor or the (Fa, Fv)-factor approach, the crux of such analyses lies in how to appropriately model and evaluate ground motion spectra in comparative context where spectral information in relation to attenuation holds primary significance [4].

To facilitate refining of this classification system, it is therefore required to better understand ground motion types and their possible interference. This will enable plausible evaluations resulting from realistic site-specific assessments relevant to the assessed motions for reliable predictions. This shall not only include adjusting or tuning of existing empirical relations but also improving data recording appropriate conditions as well as evaluation based on well-understood baseline measurements better done in time domain compared to any synthesised distributions [5].

The existing building codes, for any given purpose, are much simplistic. On the other hand, more sophisticated probabilistic seismic hazard analysis (PSHA) or spectral-based methods are somewhat generic or unrealistic because their synthesising and solution analysis draw from many earthquakes not necessarily related to the faults or disturbance sources directly influencing the site of interest, in the space-time sense. A control model comparing studies such as the Campus Earthquake Program of University of California (CEP) using realistic or real-life experimental constituents, i.e. frequencies of structural and relief artefacts, clearly provides an example or means for the critical assessment of relevance of the propriety of the existing seismic design based on site specificity. Based on the outcomes of the study, it is argued that the majority of the expected severe ground motions appear not to be consistent with basic assumptions, which are rendered inadequate [6].

Furthermore, for the past 3 decades, research in this field has adopted a site-dependent strategy, which is suggested or desired, compared to either a purely intensity-dependent strategy or a purely geotechnical description, or a strategy that relies on depth/velocity consideration. Intensity-based approach considers short- and long-period amplification factors related to the average shear wave velocity measured over the 
upper $100 \mathrm{ft}$. of a site. The geotechnical and depth-based method was further refined to account for the site effects to create normalised design spectra. The method may require expansive investigations and better incorporation or appreciation of depth to bedrock, a de-merit, along with some others such as aberrant decrease in amplification with increase in intensity and non-linearities in spectra, which renders the current code of site factors unconservative, and this should be re-evaluated by revisiting extensive resources. Apart from offering median estimation, standard error information is also provided by current ground motion attenuation relationships contained in a probabilistic distribution sense of an associated hazard assessment. Most current attenuation relationships, however, still have a simplified classification scheme for site conditions, in which all sites are divided into two or three broad classifications: e.g. rock/shallow soils, deep stiff soils and soft soils. A seismic site response and the amplification of ground motions are significantly affected by the combined effect of the dynamic stiffness of the soil and the depth of the soil. Current design practice, however, uses an oversimplified approach to soil classification (e.g. 'soil' vs. 'rock') or ignores the effect of depth by accounting only for the average shear wave velocity over the upper $100 \mathrm{ft}$. of a site profile [7]. While applying the site classification system [3], based on inclusion of both ground strength properties and profile depth, to ground motion sites from two selected recent earthquakes sites (i.e.1989 Loma Prieta and 1994 Northridge) Marek et al. evaluated the validity of the system. They suggested presentation or appreciation of the spectral amplification factors w.r.t. a baseline site condition or, more precisely, a physical reference measurement. As the suggested factors, the measure of strength and depth factors can be incorporated into an attenuation relationship for complete estimation of ground motion consistent with local soil conditions; in other words, any attenuation analyses adopted or devised should take these factors into account. Attenuation equations and associated modelling procedures for evaluating ground motion site responses are presented by [8]. By definitions of the parameters and coefficients from outlined procedures, for soil and rock classes, it is clear that the fundamental quantity of interest is $\ln (\mathrm{SA} / \mathrm{PGA})$, presented in Equation 1 and Equation 2. In these equations, $M$ is the moment magnitude, $Y$ is the spectral acceleration in units of $g, \mathrm{C} 1$ differentiates reverse and thrust earthquakes, C2, C3, C4 and C5 are well-described constants (not elaborated here on purpose), and $r_{\text {rup }}$ is the closest distance to the rupture surface. In statistical terms, the quantity provides a measure of the similarity or dissimilarity of the devised acceleration coefficients, in a spectral shape comparison sense, with reference to a standard one. Because formal origins of methods used are empirical in nature, instead of using acceleration coefficients, purely displacement ones could also be used for examining same type of ground motions. Only the second term, rate of change of distance will be replaced by displacement. Such a procedure shall also not violate capturing of the dynamic strength or competence variation effects, where statistically there should not be any change of shape when a divisor of dimension $s^{2}$ is conceptually disregarded, and there could only be a uniform unidirectional shift in any possible or examined curves. To recollect, the spectral acceleration SA, measured in $g$ units equivalent to $g$-force, describes the maximum acceleration in an earthquake of an object ( $5 \%$ damping is commonly applied in one physical dimension). The SA at different frequencies or polychromatic sense may be plotted to form a standard response spectrum. On the other hand, peak ground acceleration (PGA) is equal to the maximum ground acceleration that occurred during earthquake shaking at a specific location. PGA is equal to the amplitude of the largest absolute acceleration recorded on an accelerogram at a site during a particular earthquake, by usual definition. Earthquake shaking generally occurs in all three directions. Therefore, PGA is often split into the horizontal and vertical components.

Examination of the attenuation characteristics exacts an understanding of the underlying causative mechanisms, whereby attenuation is broadly understood as the loss of amplitude of propagating wave. It includes effects of geometrical spreading in space or with distance, the effect of the continuum filling the space as well as the type and size of heterogeneities and/or el- 
ements of dislocations contained in the continuum, relative to the propagating wavelengths, given the conservative principles.

Attenuation, as identified by [9], is an anelastic process of seismic/elastic wave energy conversion to heat, effecting a decrease in amplitude, with the frequency and phase content of the propagating wavelet altered. Considering the superposition of monochromatic modes ingrained in wave propagation as a time series, the issue of attenuation examination becomes complicated and, at times, questionable when estimating attenuation within (similar) events and between (dissimilar) events. The issues become more complicated when the individual measurements or observations as time series or signals are temporally and spatially separated.

In this regard, the concept of damping of a sinusoidal locus of oscillating continuum particles or general response representation of an oscillating system makes understanding of attenuation and attenuation mechanisms easier since it provides understanding of logarithmic decrement of the oscillation, i.e., ratio of logarithmic value of two successive amplitude peaks. In mechanistic sense, the above-cited attenuation-related effects by definition fall within anelastic and/or viscoelastic regimes as acoustic perturbations are cyclical loading analogous, with corresponding time-redistricted stress-strain states. For less-frequent perturbations, stress remains proportional to strain with full strain recovery, characterised with a relaxed modulus. If the loading is more frequent, then strain may not be fully recovered for each instance of stress, defining an unrelaxed modulus. This signifies deduction of complex and absolute dynamic moduli and corresponding compliances due to the restrictions of periodicity. The real part of a complex compliance is referred to as storage compliance and the imaginary part as loss compliance, with their significance in determining energy dissipated in unit cycle, per unit volume basis. The ratio of the energy dissipated to the maximum stored energy is defined as the specific damping capacity, denoted by $2 \pi$.tan $\varnothing$ where $\varnothing$, at times denoted by $\Delta \emptyset$, stands for friction energy loss per unit cycle. Brevity in elucidation of concept thus far is intentional; more details in theory if needed are available in [10] and [11], with the relevant references therein.

When examining wave attenuation in anelastic and viscoelastic media through non-destructive or non-intrusive evaluations, infinitely small recoverable deformations are essentially assumed by definition. Despite different definitions, a time dependence is assumed, as opposed to the provision of an instantaneous equilibration. Given the issues or points of discussion mentioned herein, [12] have described the adequate quantification of attenuation by an ultrasonic pulse transmission method used for investigating dry and saturated rocks, whereas [13], in a complementing study, have hypothesised/discussed possible wave-attenuating mechanisms of material nature. Given the micro- and macro-scale implications, [10] signify assigning rheological models to descriptions of relaxation and/or dissipative acoustic loss mechanisms, i.e. the Zener model, and imply including standard models, i.e. the Voigt and Maxwell models and/or their combinations, for dynamic analyses as well as the generation and examination of anelastic and/or viscoelastic spectra since they can mirror the acoustically stimulated response of such continua/system components, identified earlier. Such phenomena has also been examined by [14] for seismic scales with the description of possible underlying mechanisms in detail. Such aspects are also discussed in other studies [15-17] for addressing similar aspects of different problems.

While explaining the ambiguities around methods used for examination of attenuation characteristics, [18] have also drawn attention towards both the issue of loss per cycle for a cyclically loaded physical material undergoing infinitesimally small recoverable deformations, to that of an oscillator where simple logarithmic amplitude decay defines the forced response damping of the system of interest. The complex moduli, as described, are representable as follows:

$M(\omega)=M_{1}(\omega)+i M_{2}(\omega)$

$J(\omega)=J_{1}(\omega)+i J_{2}(\omega)$ 
The energy dissipated per cycle is defined as follows:

$$
\Delta \emptyset=\pi M_{2}\left|\varepsilon_{\circ}\right|^{2}=\pi J_{2}\left|\sigma_{\circ}\right|^{2}
$$

The energy stored per cycle is represented as follows:

$$
V_{\text {max }}=\frac{1}{2} M_{1}\left|\varepsilon_{\mathrm{o}}\right|^{2}=\frac{1}{2} J_{1}\left|\sigma_{\mathrm{o}}\right|^{2}
$$

The argument offered is that, since the definition and quantification of $Q$ were investigated, the information contained in the quality factor such as material strength-related terms as a ratio of the real and imaginary moduli is inadequately understood. It does not correlate to a conventional logarithmic decay defining the attenuation of a periodic oscillation. The inadequacy is described as the rate of change of the complex modulus (real and imaginary components) with frequency being not accounted for, in terms of the total stored energy, in describing the dynamic or dynamics of the modulus or strength properties, though the change is represented as of equations 1 through 4; so, the stored energy description should be understood as follows:

$$
\begin{aligned}
& V_{t}=\frac{1}{4} M_{1}\left|\varepsilon_{\circ}\right|^{2}+\frac{1}{4} \operatorname{Re}\left[\left\{M-\omega \frac{\partial M}{\partial \omega}\right\}\right] \varepsilon_{\circ}^{2} e^{2 i \omega t} \\
& =\frac{1}{4} J_{1}\left|\sigma_{\circ}\right|^{2}+\frac{1}{4} \operatorname{Re}\left[\left\{J-\omega \frac{\partial J}{\partial \omega}\right\}\right] \sigma_{\circ}^{2} e^{2 i \omega t}
\end{aligned}
$$

$$
V_{\text {max }}=\frac{\left|\varepsilon_{\circ}\right|^{2}}{4}\left[M_{1}+\left\{\left(M_{1}-\omega \frac{\partial M_{1}}{\partial \omega}\right)^{2}+\right.\right.
$$

$$
\begin{aligned}
& \left.\left.\left(M_{2}-\omega \frac{\partial M_{2}}{\partial \omega}\right)^{2}\right\}^{\frac{1}{2}}\right]= \\
& \frac{\left|\sigma_{\circ}\right|^{2}}{4}\left[J_{1}+\left\{\left(J_{1}-\omega \frac{\partial J_{1}}{\partial \omega}\right)^{2}+\right.\right. \\
& \left.\left.\left(J_{2}-\omega \frac{\partial J_{2}}{\partial \omega}\right)^{2}\right\}^{\frac{1}{2}}\right]
\end{aligned}
$$

Given this discussion, the possibilities of defining or understanding $Q$ appear as follows:

$Q=\frac{4 \pi V_{a v g}}{\Delta \emptyset}$

or more simply, as of the following description, given the understanding of the parameters:

$Q=\frac{M_{1}}{M_{2}}=\frac{J_{1}}{J_{2}}$

$Q^{-1}=\frac{M_{2}}{M_{1}}=\frac{J_{2}}{J_{1}}$

Phenomenologically, given the parametric and dimensional understandings, Equation 2 of [13] has the same form as equations 8 and 9 above, where additional scaling factors only account for the degree of heterogeneity within geometrical restrictions. Apart from that, while describing the experimental attenuation measurements upon their analogues, equations 4 and 5 arrived at by [12] and [13] for spectral comparisons (spectral ratio curves) have the same meaning as equations 1 and 2 of [8]. Essentially slope-intercept form equations, where the degree of slope describes the attenuation and quality. The discussion of the theory thus far connects the underlying rationale for analogue experiment providing a basis towards understanding the details of analyses of a geotechnical nature but with direct bearings on displacement or motion analyses associated with site investigation in earthquake engineering. The analogous comparison of methods of attenuation examination in the laboratory by [12] and at the regional scale by [8] not only tends to rationalize the problem at hand but also emphasises examining or devising improved and relevant consistent ways of examining ground motions in terms of attenuation and/or amplification, as by [19], especially site-specific and near-field issues. 


\section{Discussion and illustration of results}

In furthering the discussion towards the objective of examining the $\mathrm{S}$-wave displacements from the perspective of ground motions, the data is first discussed in the illustration sense. Understanding and structuring data not only are essential in such evaluations but central to the explanation and examination of the case at hand. Figure 3 represents a windowed time domain section of the pre-stack type of ultrasonogram as a typical example for the way in which the data is acquired with the objective of capturing direction and rheological effects, for examining aspects such as attenuation characteristics. The section represents the data acquired for Load step 1 when the source and receiver aligned together are angularly displaced (or azimuth varied) through $30^{\circ}$ increments and measurements made at each incremented azimuth. The waveforms forming the time domain section in graphical resolution are adjusted to allow the ready understanding of the (i) nature and consistency of the anatomical character of a single acquired waveform or trace as a measurement and (ii) the apparent variability of waveform polarisation in correspondence to acquisition method, and possible implications, details of which are shown in Figure 2. Figure 4 a further confirms the quality and adequacy of the measurements in terms of preservation of anatomical character of waveform signal or trace in reciprocity. It can be easily observed that when either the source or the receiver is at $30^{\circ}$ w.r.t. the fracture planes and the other parallel to them, the acquired signal character is identical.

Similar can be confirmed by observation of Figure $4 \mathrm{~b}$, for, when either the source or the receiver is oriented at $60^{\circ}$ relative to the fracture plane while the other is parallel, there is no principal difference in the observation or character of measurement. In this way, all reciprocal combinations for both source and receiver were examined, wherein the source was angularly displaced $0^{\circ}$ through $180^{\circ}$ in $30^{\circ}$ steps and at each step, the receiver was displaced through similarly $0^{\circ}$ through $180^{\circ}$. Deducibly so, same reciprocity was observed in the observations depicted by Figure 3 and/or Figure 5, where-

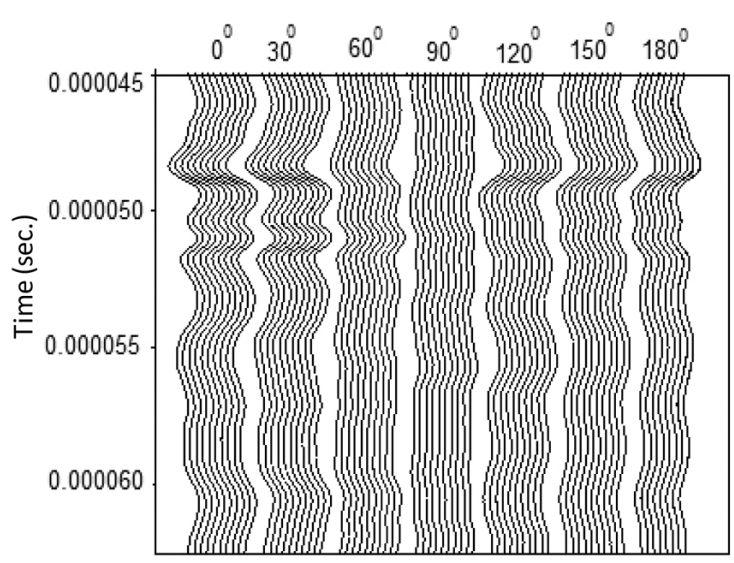

Figure 3: Pre-stack waveforms recorded at Load step 1 for $S$-wave ultrasonic receiver sensor (or transducer) at $0^{\circ}$ and receiver angularly rotated or displaced from $0^{\circ}$ through $180^{\circ}$ in $30^{\circ}$ increments with respect to the fracture planes.

as any minor observable aberrations only correspond to a failure of precisely repeating the sensor angular adjustments and alignment given the resolving capability or the sensitivity and size of the sensor elements. Figure 5 shows a full $0.1 \mathrm{~ms}$ duration ultrasonic trace given causality. Presentation or organisation of waveform traces, as such, allows the estimation or determination of ultrasonic velocities with accuracy by identifying the first breaks and observing the variabilities of magnitude, and those possibly associated with phase could be identified for further examination.

In the context of the discussion in progress, given the analysis thus far, two different velocities could be interpreted given a single energy source and receiver station, in analogy. The velocities correspond to two different time delays, either distances or modes. Amplitude polarisation and magnitude sensitivity to fracture orientation are also shown in Figure 6. In this regard, on the same lines discussed thus far, from the pre-analyses, several post-stack ultrasonograms, of the type shown for Load step 1 in Figure 6, were constructed for all load steps (1-9) finally.

These are not presented only because they were identical in presentation, and mutually informed or bore stress-related information only, as discussed earlier in the context of spectral examination, to advantage. Two velocities at each load step, maximum at source and receiver parallel to and minimum at source parallel at 

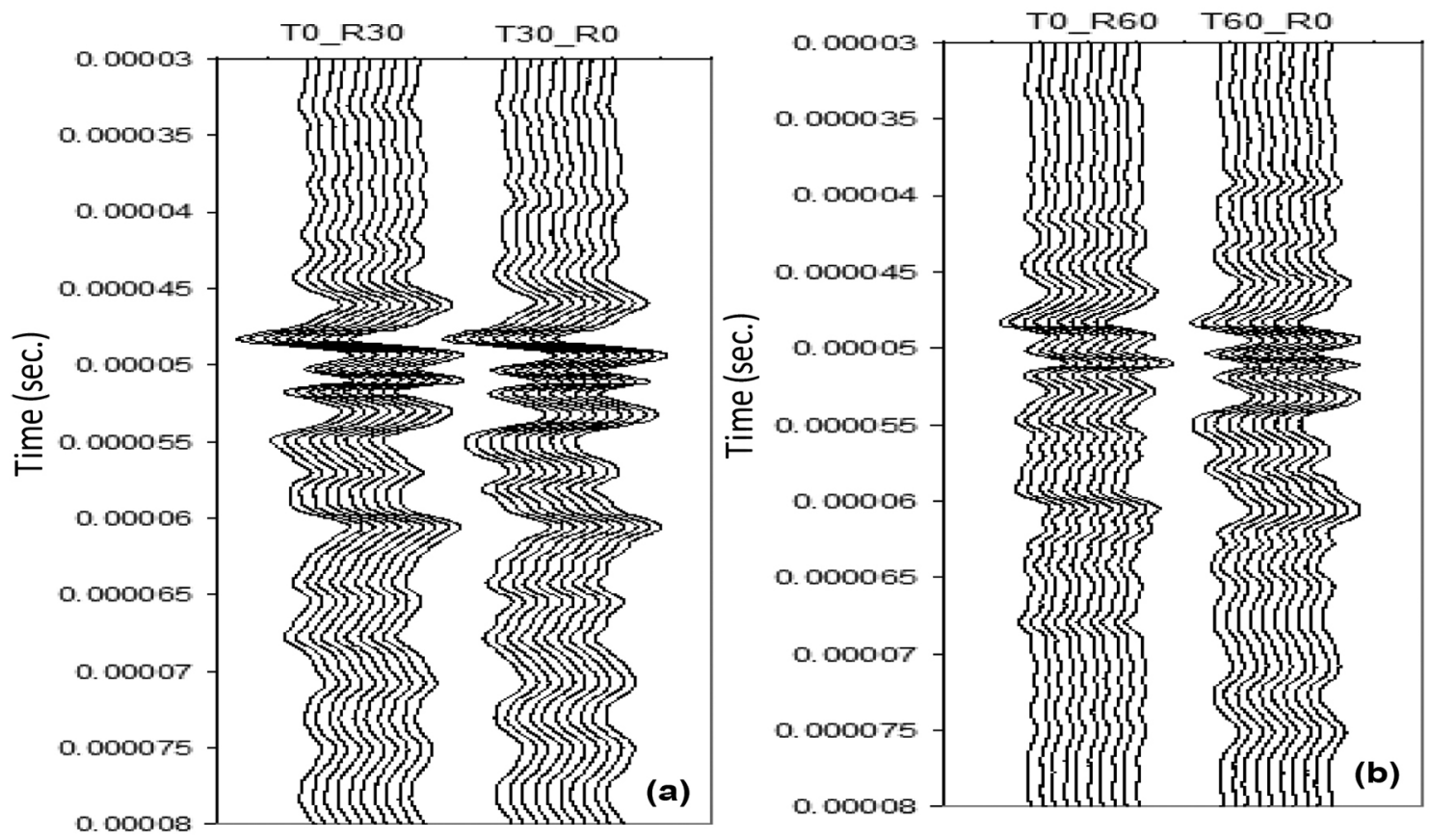

Figure 4: Confirmation of source and receiver reciprocity of acquisition due to symmetry to confirm consistency of sensor response, adequacy of data acquisition strategy to allow data reduction, as responses are similar for (a) source at either $0^{\circ}$ or $30^{\circ}$ w.r.t. fractures, while the receiver is at $30^{\circ}$ and $0^{\circ}$; correspondingly (b) is same as (a) for $60^{\circ}$ angular displacements.

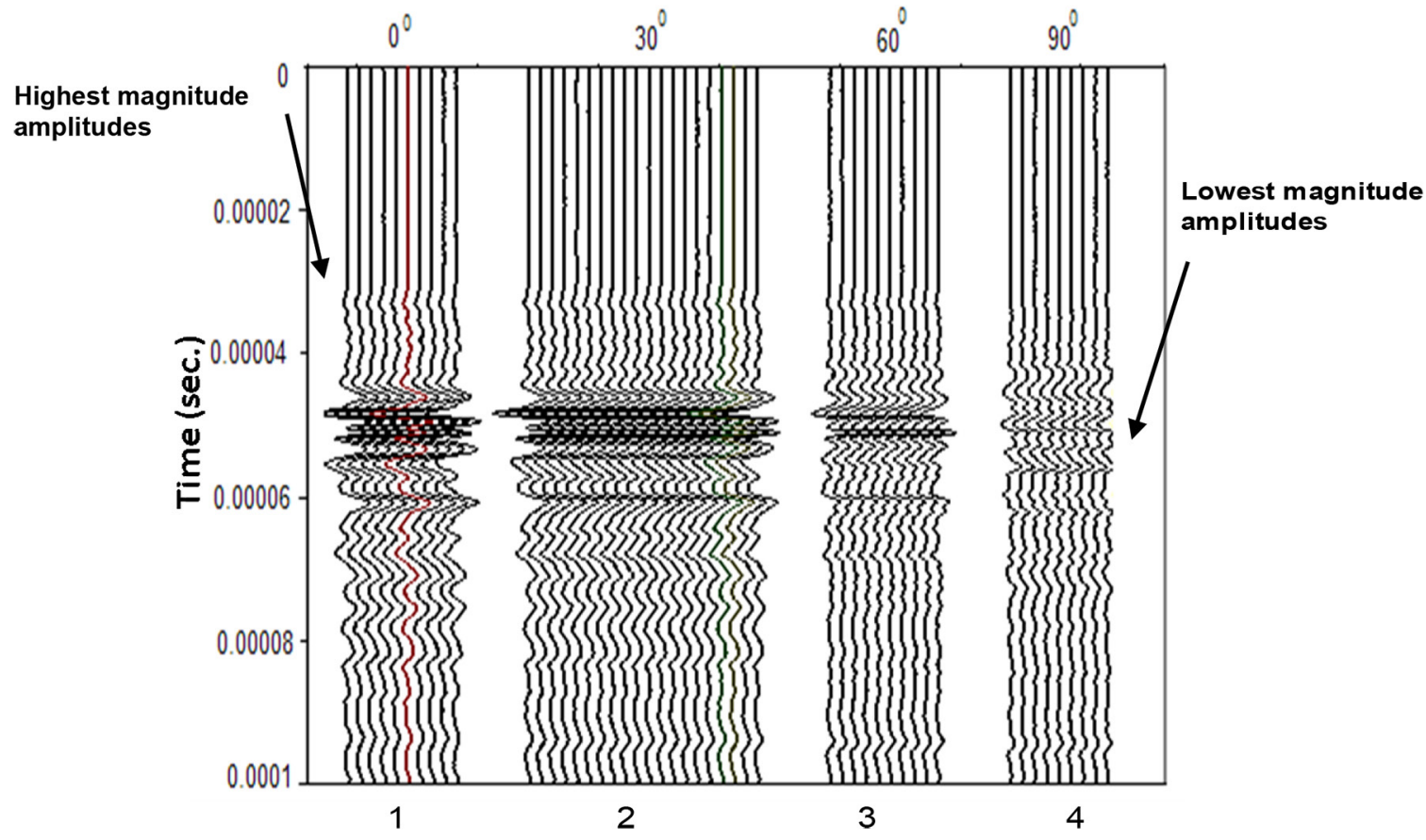

Figure 5: Half of data of section of Figure 3 shown in full $0.1 \mathrm{~ms}$ duration pre-stack waveforms to reveal apparent amplitude loss with azimuthal or source-receiver relative angular displacement variation w.r.t. fracture orientation for Load step 1, i.e. amplitude is maximum when source and receiver are both at $0^{\circ}$ or parallel w.r.t. fractures, i.e. stack 1 , and minimum when the receiver is angularly displaced to $90^{\circ}$ or perpendicular w.r.t. fractures, i.e. stack 4. 

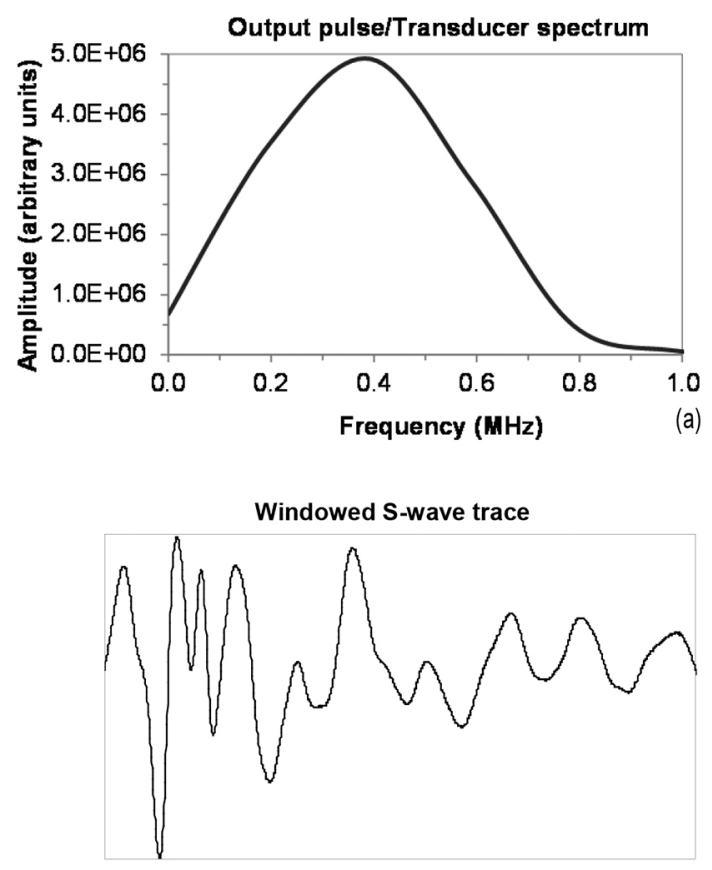

(c)
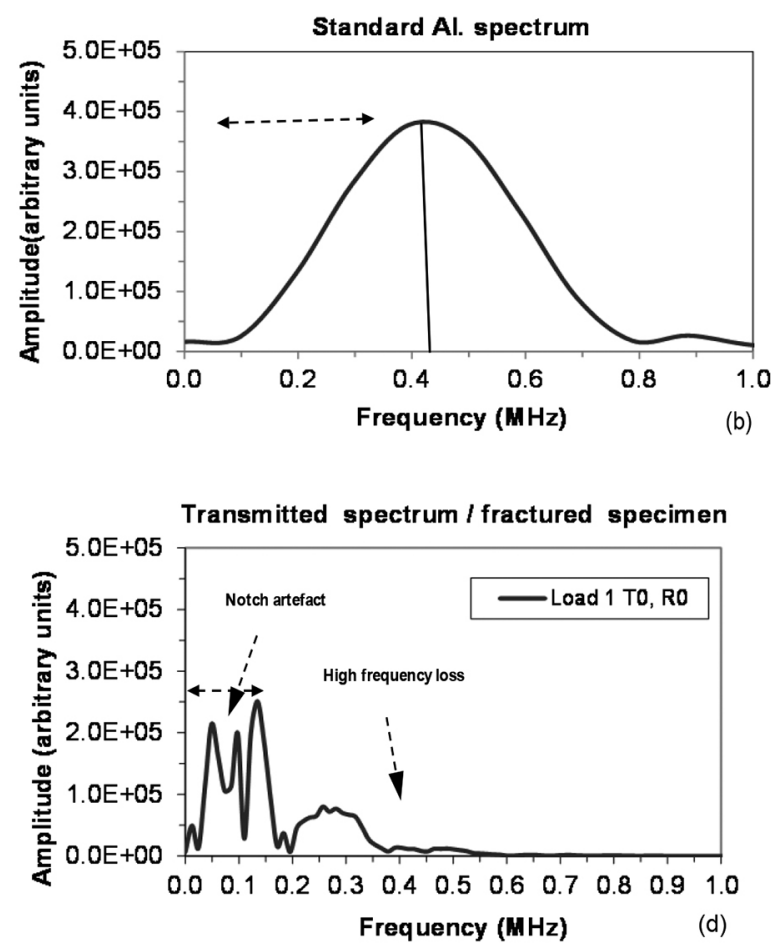

Figure 7: Some baseline measurements for spectral distribution and spectral ratio evaluation. (a) Measured S-wave input spectrum/transducer or sensor output. (b) A reproducible high Q aluminium spectrum. (c) Time-irrespective windowed S-wave maximum energy concentration trace for Load step 1 and orientation $\left(T 0_{-}^{\circ} R 0^{\circ}\right)$, i.e. transmitted at $0^{\circ}$ and received at $0^{\circ}$ w.r.t. fracture trajectory.

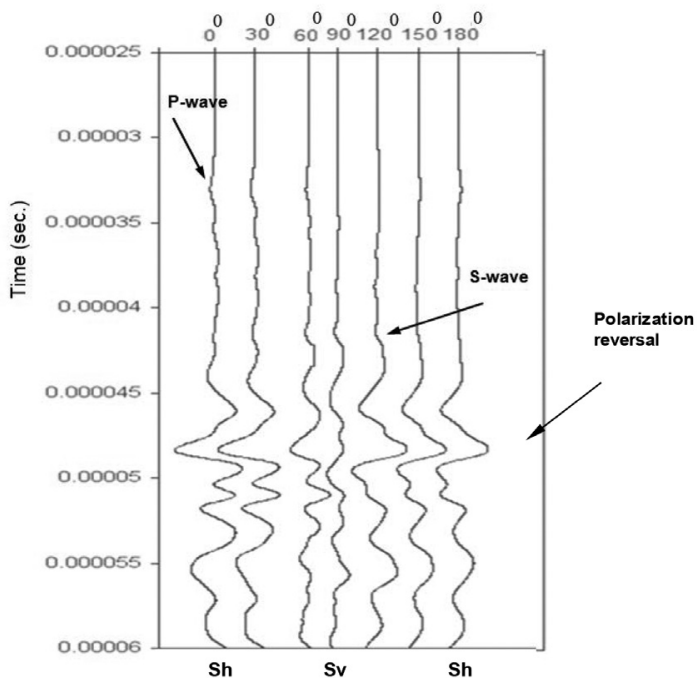

Figure 6: Post-stack ultrasonogram from information of Figure 3 and Figure 5 for Load step 1 only. Mode converted Pand legitimate $S$-wave first breaks could be identified. Maximum S-wave arrival delay and minimum amplitude were at $90^{\circ}$, and minimum delay and maximum amplitude were at $0^{\circ}$ and $180^{\circ}$. All ultrasonograms for Load steps 1-9 had identical features, with shifts of arrival time delays of corresponding wave forms as a decrease with stress. $0^{\circ}$ but receiver perpendicular at $90^{\circ}$ w.r.t. fracture planes, were identified.

The maximum velocity varied from $2700 \mathrm{~m} / \mathrm{s}$ to about $2740 \mathrm{~m} / \mathrm{s}$, and minimum velocity variation was $2500 \mathrm{~m} / \mathrm{s}-2575 \mathrm{~m} / \mathrm{s}$, i.e. VSh and VSv, given the stress variation information in Figure 2 . The velocity difference and splitting of S-waves in reconstructed or recorded signal is controlled by symmetry-associated preferential polarisation. This phenomenon could be understood from previous studies [20,21], and given the rationale of this exposition, in the review by [22] along with references there in, as further discussion of this is out of the scope of this paper.

The information of travel time delays identified in a single source and receiver station scenario is not sufficient to examine the dynamic response of the experimental analogue against any elastic stimulation under variable stress. The effect, though, of heterogeneity and stress could be speculated from different ultrasonograms of different times, i.e. several load steps; further resolution, however, could only be 
achieved by well-designed spectral comparison and ratio evaluations.

Figure 7, hence, emphasises generating repeatable measurable standard spectra for realistic and conceptually portable evaluations. Figure $7 \mathrm{a}$ shows the frequency spectrum for the source $S$-wave transducer or transmitter. For determining sensor adequacy in terms of adequacy of bandwidth w.r.t subsequent measurements; the source and receiver transducer sensing surfaces were held in direct contact to both re-sample and regenerate the source spectrum. The same spectrum was transmitted as input through the conceptually non-attenuating aluminium (conceptually infinite $Q$ ) reference specimen to create a standard physically reproducible aluminium spectrum.

The spectrum of Figure 7a was used as the input in all the discussed measurements for consistency of signal strength while investigating the fractured porous media specimens, including those graphically presented. The reason for using aluminium sample to generate a standard spectrum or response was to attain consistency of geometrical aspects and statistical adequacy, apart from reproducibility and portability, in analyses. The aluminium cylindrical specimen used was identical in length and diameter to the sandstone core out of which the slabs were cut to synthesise the analogue by their symmetric stacking. Secondly, the space of constitution of the aluminium sample was continuous and uniform throughout compared to the porous fractured analogue's heterogeneities of architecture, structure and matrix material. In terms of the rationale of the exposition, the aluminium sample served for a spatially isolated but characteristically comparable competent site liable to be used for making standard time domain or time series measurements for extendable and scalable comparative evaluations, as shown in subsequent elucidation.

Figure $7 c$ is a typical time-irrespective maximum energy or information-windowed waveform corresponding to Load step 1, where a similar windowing strategy was applied for generating the frequency spectra by the fast Fourier transform (FFT) method with a consistent sampling frequency. Figure $7 \mathrm{~d}$ is the spectrum for the waveform of Figure $7 \mathrm{c}$ corresponding to the $0^{\circ}$ trace of Figure 6 . Figure $7 d$ assumes some significant feature leading to an eventual discussion. It is readily observable that the spectrum of Figure $7 \mathrm{~d}$ is much more attenuated in proportion compared to that of Figure $7 b$, w.r.t. that of Figure 7a. Such kind of attenuation clearly suggests a remarkably different material, heterogeneous and presumably porous. Apart from that, the frequency shift from $300 \mathrm{KHz}$ to $150 \mathrm{KHz}$, towards the lower end, in comparison also suggests that the material is less stiff. Further, though the high-frequency side of the response is completely dissipated, the spectrum could still be divided into lower-magnitude and higher-magnitude frequency contents at $200 \mathrm{KHz}$. This may indicate that both macro- and micro-structure are manifested as the notch type effect clearly corresponds to the presence of fractures or ordered structure, as in [23] and associated works.

In Figure 8, the same spectrum as in Load step $1\left(0^{\circ}\right.$, Sh orientation of Figure 6$)$ is shown in combination with that of Load step 9 for mutual comparison. Interestingly, there is no significant difference in the spectral magnitude in magnification context or from a diagnostic evaluation context. The shift of relatively higher-frequency content towards low-frequency energy only suggests that with the possible collapse of some microstructure and any asperities associated with the fracture surface, the primary structural information is retained for a more compact and integral structure, compared to a fragmented structure. This is to say that with no significant increase, given the nature of the Sh polarisation, in displacements, the effect of stress upon Sh displacement communication is negligible to zero value in terms of displacement transmission; however, this is not a completely dissipating one.

The spectral ratios in Figure $8 \mathrm{~b}$ show more detail. Given the frequencies of interest, the negative spectral ratio reveals a sense of lack of stiffness or competence in terms of frequency shifts. In technical terms, it is not unrealistic for the manner in which the method is used, i.e. Ln (1) $=0$. From this fact, one could conclude that Sh motions are more attenuated under increased fracture-normal stress. This is possibly for friction reintroduction, as opposed to when subjected to a lesser degree of normal stress, 

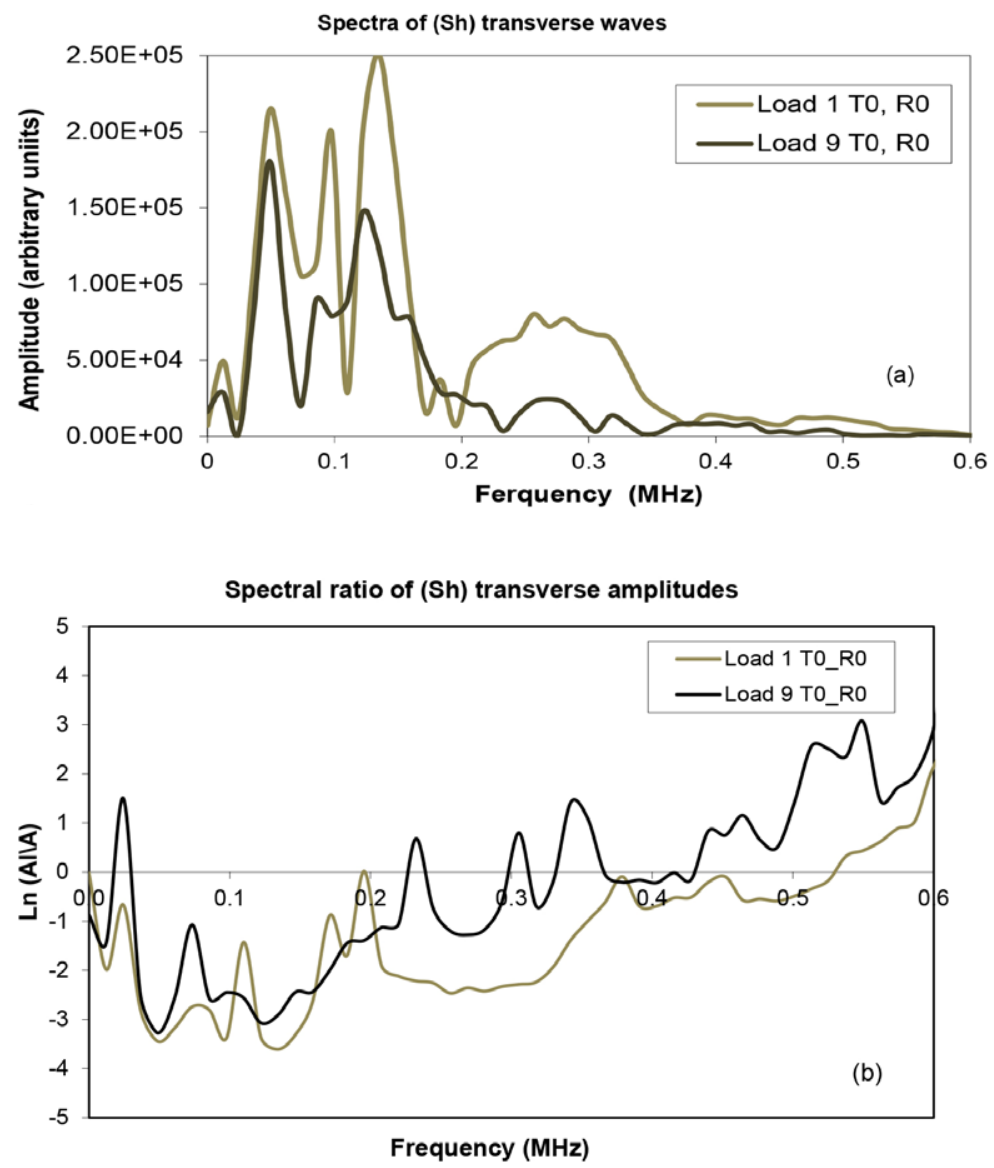

Figure 8: (a) Spectral distribution and (b) spectral ratios of Sh or transverse waves for Load steps 1 and 9 compared.

given the slope of the curves and the spectrum of Figure $7 \mathrm{~b}$ being taken into account for the case at hand, though apparently counter-intuitive.

The Sv displacements spectra depicted in Figure 9a, examined on the same line of argumentation as for Figure 8a, contain the same kind of information but lead to a different inference. For Load step $1\left(90^{\circ}\right.$, Sv polarisation of Figure 6), the spectral amplitudes are much less in magnitude; however, the predominant frequency of $500 \mathrm{KHz}$ is retained, confirming the fundamental response of the structure, while the rest of the bandwidth is significantly attenuated or filtered out. However, the spectrum for Load step 9 is significantly amplified proportionately. This is due to the fact that the nature of displacement is a pressure wave, comparably susceptible more to stiffness than to the effects of fracture plane contact friction, thus appearing minimal.
Apart from this, the structure-related features as identified are also revealed due to the fracture contact or interfaces, causing reflection-associated tuning-controlled transmission modes.

In terms of evaluating the spectral ratios for $\mathrm{Sv}$ motions or dilatations (displacement amplitudes), it is clearly in conformity with previous examination that negative attenuation within the bandwidth of interest clearly depicts the incompetence of the analogue structure w.r.t. the standard spectrum of Figure $7 \mathrm{~b}$. The overall character of the curves is more intuitively linear, in comparative context, whereby with an increase in stiffness affected by load or a normal stress increase on the fracture plane, attenuation of displacements decreases, and amplification increase in an energy sense occurs. Additionally, without apriori knowledge, which usually may be available, the fracture orientation and direction from a multi-compo- 

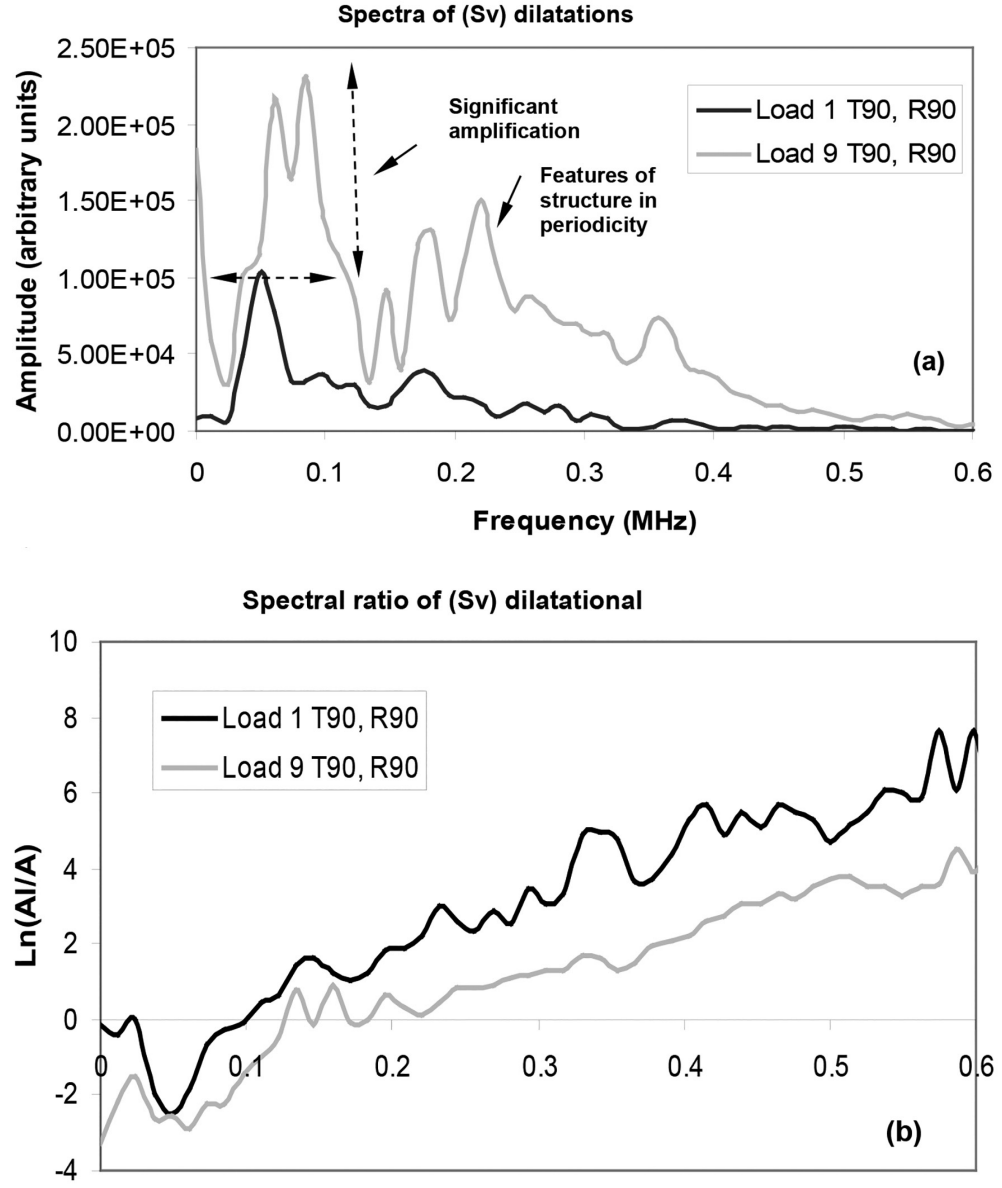

Frequency (MHz)

Figure 9: (a) Spectral distribution and (b) spectral ratios of Sv or dilatational waves for Load steps 1 and 9 compared.
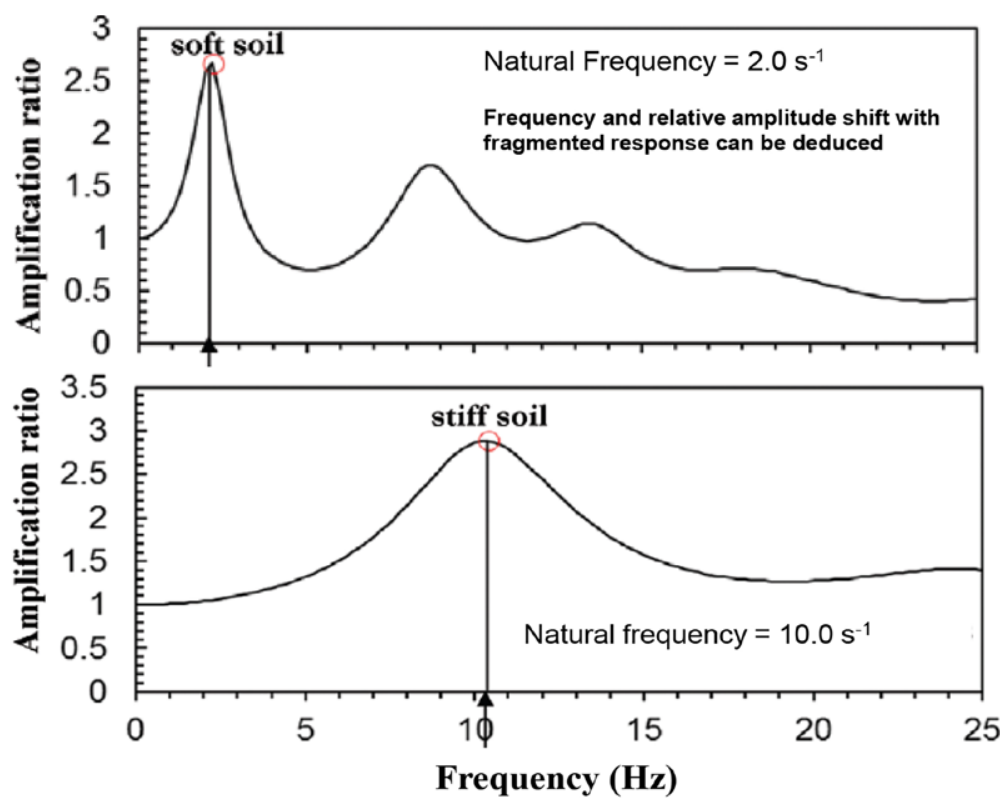

Figure 10: An example of amplitude and frequency shifts (soft vs. stiff soil) for examining relative amplification by spectral comparison (modified from [24]). 
nent data could also be determined and spacing could also be estimated, as was performed in other extended analyses reported by Hassan [2].

In comparing the evaluations of Figure 8 and Figure 9, it could be deduced that behaviour is more of a non-linear and friction controlled, in comparison to the case of Sv-associated deformations, where stress effects are predominant. However, increase of normal stress to fractures definitely causes amplification of deformation response under dynamic load stimulation, expected proportionately more in the direction of Sv or P-wave mode polarisation.

Site or ground classification in terms of competence determination by means of spectral matching or examination of the spectral shape or anatomy has also been done for different geo-materials or ground scenarios during the course of studies $[15,16]$, while signifying inherent implications of duration and sampling density in time series sense. A similar procedure in workflow concept is suggested by [24], pictorially described in Figure 10, from where other concepts and references could be followed.

\section{Conclusions}

Analyses of geotechnical nature based purely on sound physical or geophysical principles of investigating into ground motion evaluations are valid for site-specifying purposes. The proposition is due to the fact that the methods based on generating and matching relative accelerogram spectra are quite empirical and predictive only. There appears exactingness for rather unique and more control-type time-restricted or time domain measurements, to minimise the duration or time distribution of energy-related issues not translated to spectra appropriately. Findings based solely or uniquely upon Sv and Sh polarisation examinations of an experimental analogue stimulated by $\mathrm{S}$-waves suggest that in fractured bedrocks or strata possibly supporting topsoil, there is less chance of amplification for polarisations along the fracture planes, while there is a significant chance of displacement amplitude amplification normal to the fractures in the direction of variation of the normal stress. Spectral matching and spectral ratio examination based on standard measured spectrum show that normal stress increase upon fracture contact surface amplifies Sv dilatational displacements significantly, showing up as peculiar amplitude and frequency shifts compared to Sh transverse displacements, which definitely appear to be more friction controlled. Apart from refining existing empirical procedures for ground motion-based site evaluations; experiments using physical analogues to investigate the nature of generation and interaction of ground motions for different physical topologies may lead to more generic methodologies. Such control experiments can be usefully promoted from the laboratory not only to the local scale above more predictive regional-scale ones but also to a material characterisation scale to an advantage.

\section{Acknowledgements}

Our thanks and appreciation for the funding received from NSERC, NSERC Research and Discovery and PRNL (Petroleum Research Newfoundland and Labrador). Discussion around propriety of translation of duration aspects of time series to spectral content, given convolution theorem, was conducted with Oz Yilmaz (oz@anatoliangen.com) of Anatolian Geophysical at SAGEEP 2015.

\section{References}

[1] Frempong, P., Donald, A.,Butt, S.D. (2007): The effect of pore pressure depletion and injection cycles on ultrasonic velocity and quality factor in a quartz sandstone. Geophysics, 72 (2), pp. E43-E51. doi: 10.1190/1.2424887.

[2] Hassan, B. (2017): Investigation of integrated geophysical methods to characterize near surface formations for enviromental engineering. Ph.D. Thesis.St. John's: Memorial University of Newfoundland, Canada 2017; 68,87,91 p.

[3] Marek, R.A., Bray, J.D., Abrahamson, N. (1999): Task 3: Characterization of Site Response: General Site Categories. In: PEER Report 1999/03. Pacific Earthquake Engineering Research Center, Pacific Gas and Electric Company and David and Lucile Packard Foundation, University of California: Berkeley; pp. 1-36. 
[4] Dobry, R., Borcherdt, R.D., Crouse C.B., Idriss, I.M., Joyner, W.B., Martin, G.R., Power, M.S., Rinne, E.E., Seed, R.B. (2000): New site coefficients and site classification system used in recent building seismic code provisions. Earthquake spectra, 16 (1), pp. 41-67. doi:10.1193/1.1586082.

[5] Abrahamson, N.A., Silva, W.J. (1997): Empirical Response Spectral Attenuation Relationships for Shallow Crustal Earthquakes. Seismological Research Letters, 68(1), pp. 94-127.

[6] Heuze, F., Archuleta, R., Bonillab, F., Day, S., Doroudian, M., Elgamal, A., Gonzales, S., Hoehler, M., Lai, T., Lavallee, D., Lawrence, B., Liu P.C., Martin, A., Matesic, L., Minster, B., Mellors, R., Oglesby, D., Park, S., Riemer, M., Steidl, J., Vernon, F., Vucetic, M., Wagoner, J., Yange, Z. (2004): Estimating site-specific strong earthquake motions. Soil Dynamics and Earthquake Engineering, 24, pp. 199-223. doi: 10.1016/j.soildyn.2003.11.002

[7] Marek, A.R., Bray J.D., Abrahamson, N.A. (2000): A Geotechnical Seismic Site Response Evaluation Procedure. In: Proceedings of $12^{\text {th }}$ World Conference on Earthquake engineering,12WCEE Aukland, New Zealand; pp. 1590.

[8] Sadigh, K., Chang, C.Y., Egan, J.A., Makdisi, F., Youngs, R.R. (1997): Attenuation Relationships for Shallow Crustal Earthquakes Based on California Strong Motion Data. Seismological Research Letters, 68 (1), pp.181-189.

[9] Jones, T.D. (1986): Pore fluids and frequency-dependent wave propagation in rocks. Geophysics, 51(10), pp.1939-1951.

[10] Nowick, A.S., Berry, B.S. (1972): Anealastic relaxation in crystalline solids. New York: Academic Press Inc.

[11] Bourbie, T., Coussy, O., Zinszner, B.(1987): Acoustics of porous media. Paris: Gulf publishing company.

[12] Toksoz, M.N., Johnston, D.H.,Timur, A. (1979): Attenuation of seismic waves in dry and saturated rocks: I. Laboratory measurements. Geophyscis, 44, pp. 681-690.

[13] Johnston, D.H., Toksoz, M.N.,Timur, A. (1979): Attenuation of seismic waves in dry and saturated rocks: II. Mechanisms. Gephysics, 44, pp. 691-711.

[14] Berryman, J.J. (1988): Seismic wave attenuation in fluid-saturated porous media. Pure and Applied Geophysics, 128, 423-432.
[15] Hassan, B., Butt, S.D., Hurich, C.A. (2014): Evaluation of time lapse acoustic monitoring of immiscible fluid flows in near surface by attenuation examination method. In: EAGE Proceedings of 20th Eupropean meeting of Environmental and Engineering Geophysics, Athens, Greece, p. 22321.

[16] Hassan, B., Butt, S.D., Hurich, C.A. (2015): Ascertaining grain scale effects of sesimic or aseismic stimulation upon strength of nearsurface geological matierials. In: EAGE Proceedings of 21st European Meeting of Environmental and Engineering Geophysics, Turin, Italy, p. 26254.

[17] Hassan, B., Butt, S.D., Hurich, C. A. (2017): Ascertaining Grain Scale Effects Of Seismic Or Aseismic Stimulation Upon Strength Of Near Surface Geological Materials. International Journal of Scientific \& Technology Research, 6(2), pp. 74-78.

[18] O'Connell, R.J., Budiansky, B. (1978): Measures of Dissipation in Viscoelastic Media. Geophysical Research Letters, 5(1), pp.5-8.

[19] Douglas, J. (2003): Earthquake ground motion estimation using strong-motion records: a review of equations for the estimation of peak ground acceleration and response spectral ordinates. Earth Science Reviews, 61, pp. 43-104.

[20] Waterman, P.C., Teutonico, L.J. (1957): Ultrasonic Double Refraction in Single Crystals. Journal of Applied Physics, 28, pp. 266-270; DOI: 10.1063/1.1722721.

[21] Booth C.D., Crampin, S., Chesnokov, E.M., Krasnova, M.A.(1986): The effect of near vertical cracks on shear-wave polarizations. Geophysical Journal of Royal Astronomical Society, 87, pp. 583-594.

[22] Crampin, S. (1987): The basis for earthquake prediction. Geophysical Journal of Royal Astronomical Society, 91, pp.331-347.

[23] Nolte, D.D., Nolte, L.P., Beach, J., Zeigler, C. (2000): Transition from the displacment discontinuity limit to the resonant scattering regime for fracture interface waves. International journal of rock mechanics and mining sciences, 37 (1), pp. 219-230.

[24] Yilmaz, O. (2015). Engineering Seismology with Applications to Geotechnical Engineering, Investigations in Geophysics Series No.17, Tulsa, Ok: Society of Exploration Geophysicists, 721 p. 